\title{
Antimicrobial Activity, Spectral Studies and Micellar Properties of Some Surfactant-Cobalt(III) Complexes
}

\author{
K. SASIKALA ${ }^{* a}$ and S. ARUNACHALAM ${ }^{b}$

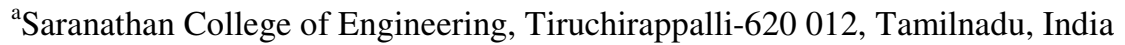 \\ ${ }^{\mathrm{b}}$ School of Chemistry, Bharathidasan University, Tiruchirappalli-620 024, Tamilnadu, India \\ s.sasi11981@gmail.com
}

Received 15 January 2013 / Accepted 15 February 2013

\begin{abstract}
Some new surfactant-cobalt(III) complex ions of the type, cis- $\left[\mathrm{Co}(\mathrm{X})_{2}\left(\mathrm{C}_{11} \mathrm{H}_{23} \mathrm{NH}_{2}\right)_{2}\right]^{3+}$ (where $\mathrm{X}=$ ethylenediamine or 2,2' bipyridyl or 1,10-phenanthroline) and cis- $\alpha$-Co(trien) $\left.\left(\mathrm{C}_{11} \mathrm{H}_{23} \mathrm{NH}_{2}\right)_{2}\right]^{3+}$ were synthesized and characterized by IR, NMR, UV-Visible spectra, elemental and metal analysis. The critical micelle concentration (CMC) values of these surfactant-cobalt(III) complexes in aqueous solution were obtained from conductance measurements. Specific conductivity data (at 298, 308 and $318 \mathrm{~K}$ ) served for the evaluation of temperature-dependent CMC and the thermodynamics of micellization $\left(\triangle \mathrm{G}_{\mathrm{m},}^{0} \Delta \mathrm{H}_{\mathrm{m}}^{0}, \triangle \mathrm{S}_{\mathrm{m}}^{0}\right)$. The surfactant-cobalt(III) complexes were screened for their antibacterial and antifungal activities against various microorganisms. The results were compared with the standard drugs, ciprofloxacin and fluconazole respectively. The surfactantcobalt(III) complexes showed good antimicrobial activity against gram positive and gram negative bacteria and fungi. Thus our results show that the surfactant-copper(III) complexes can also be considered for antifungal and antibiotic drugs.
\end{abstract}

Keywords: Surfactant-cobalt(III) complex, Antimicrobial activity, Fluconazole, Cifrofloxacin

\section{Introduction}

Surfactant- metal complexes have received a sustained level of attention ${ }^{1-6}$ due to their relevance in various redox processes in the biological system and are promising agents as anthelmintics $^{7}$, antiparasitics ${ }^{8}$, antibiotics ${ }^{9}$ and because of their multiple applications in fields such as medicine ${ }^{10}$, magnetic resonance imaging ${ }^{11}$ and drug delivery ${ }^{12}$. Surfactantmetal complexes with chelating ligands are of interest for metallobiomolecules in the search for appropriate systems for binding and activating simple molecules, catalysis and magnetic interactions $^{2,13}$. Surfactant-metal complexes are a special type of surfactants, where a coordination complex acts as the surfactant. In these surfactants, the metal complex containing the central metal ion with its primary coordination sphere acting as the head group and the hydrophobic part of one or more ligands acts as the tail. Like other wellknown surfactants, these metallosurfactants also form micelles at a specific concentration called critical micelle concentration (CMC) in aqueous solution.

$†$ Presented to the National Conference on Chemistry Solutions at SRM University, India 
There are some reports ${ }^{14-19}$ on the synthesis, isolation and characterization of surfactanttransition metal complexes. Jaeger et al. have reported the synthesis of cleavable doublechain surfactant cobalt(III) complexes ${ }^{14}$. Viscardi et al. studied the synthesis, surface and antimicrobial properties of novel cationic surfactants named gluco-pyridinium surfactants. Here the glucose moiety was inserted in to the surfactant molecule, thus modifying the head group polarity ${ }^{20 .}$ Wanles have reported the surface properties of cationic cage surfactant which consisted of a macrocyclic hexamine cage surrounding a cobalt(III) ion and a branched hydrocarbon tail and also the aggregation behaviour of this complex surfactant was determined using the law of mass action and assuming a constant degree of counterion binding to the micelle ${ }^{21}$. Fallis et al. have studied the synthesis and characterization of novel $\mathrm{Ni}(\mathrm{II})$ and $\mathrm{Cu}(\mathrm{II})$ based surfactants and also the solid state and solution behaviour of novel transition metal containing surfactants which have been determined by x-ray crystallography ${ }^{22}$. Hafiz et al. have reported the synthesis and characterization of some cationic surfactants. The physical properties of the synthesized surfactants including electrical conductivity, critical micelle concentration of and the degree of ionization of the micelle $(\beta)$ were studied ${ }^{23}$.

A characteristic feature of transition metals is their ability to form complexes with a variety of neutral molecules such as bipyridine (bpy) and phenanthroline (phen). These are widely used as a classical $N, N$ - bidentate ligand to prepare mixed-ligand complexes in coordination chemistry. Metal complexes of bipyridine and phenanthroline chelators are of great interest since they exhibit numerous biological properties such as antitumor, anticandida and antibacterial activity ${ }^{24-26}$. At the same time, metal complex bearing ethylenediamine have also been interest because in the classical antitumor agent cisplatinum, one of the ligands must be a $\mathrm{N}$-donor and posses at least one hydrogen atom attached to the nitrogen $^{27}$.

Cobalt(III) complexes, by virtue of their abundance and diversity, have played a fundamental role in our understanding of the structural, spectroscopic and electrochemical properties of coordination compounds. We have been interested in the synthesis and micelle forming properties of cobalt(III) complexes containing lipophilic ligands for a long time ${ }^{28-30}$. As in biology, such compounds may exhibit novel physical and chemical properties with interesting and useful associated applications.

Because of great effort and success in the study of metallosurfactants of cobalt(III) complexes, such complexes have attracted much attention due to their interesting properties and the relative simplicity of their synthesis. In this article we report the synthesis, characterization and determination of CMC values of some surfactant-cobalt(III) complexes. Also we have reported the antibacterial and antifungal activities of these surfactantcobalt(III) complexes against certain human pathogenic microorganisms.

\section{Experimental}

All the reagents were of analytical grade (Aldrich and Merck). Ultra pure water obtained by deionising distilled water using a milli-Q reagent grade water system was used for the preparative work and to make up solutions for all physical measurements.

\section{Microorganisms}

The test bacterial strains were: Salmonella typhimurium NCIM 2501 (B1), Vibrio cholerae MTCC 3906 (B2), Micrococcus luteus NCIM 2871 (B3), Enterococcus faecalis MTCC 439 (B4) and Shigella flexneri MTCC 1457 (B5). The test fungal strains were: Candida albicans 
MTCC 1637 (F1), Candida glabrata MTCC 3984 (F2) and Cryptococcus sp MTCC 7076 (F3), Microsporum canis MTCC 3270 (F4) and Epidermophyton floccosum var. nigricans MTCC 613 (F5).

All the test bacteria were grown in nutrient agar medium and incubated at $37 \pm 1{ }^{\circ} \mathrm{C}$ for 24-48 $\mathrm{h}$ followed by frequent subculture to fresh (Nutrient broth) medium and were used as test bacteria. All the test fungal cultures grown into potato dextrose agar (PDA) medium, incubated at $25 \pm 1{ }^{\circ} \mathrm{C}$ for $72 \mathrm{~h}$ followed by periodic sub culturing to fresh mycological broth medium and were used as test fungus. All the media and standard disks were purchased from Hi-Media (Mumbai, India). The test cultures were obtained from NCIM and MTCC.

\section{Methods}

Absorbtion spectra were recorded on a UV-VIS-NIR cary 300 spectrophotometer using cuvettes of $1 \mathrm{~cm}$ path length, FT-IR spectra were recorded on a FT-IR spectrofluorimeter with samples prepared as $\mathrm{KBr}$ pellets. ${ }^{1} \mathrm{H}$ and ${ }^{13} \mathrm{C}$ NMR spectra were recorded on a BRUKER $400 \mathrm{MHz}$ Spectrometer using DMSO as solvent. Conductivity studies were done in aqueous solutions of the complexes with an Elico conductivity bridge type CM 82 and a dip-type cell with a cell constant of 1.0.

\section{Synthesis of double chain surfactant-cobalt(III) complexes}

The surfactant-cobalt(III) complexes of the present study were prepared as given below using a method similar to the same type of complexes reported in the literature as well as in our previous work ${ }^{8,30}$.

To a solution of appropriate amount of cis- $\left[\mathrm{Co}(\mathrm{X})_{2}(\mathrm{Cl})_{2}\right] \mathrm{Cl}$ where $\mathrm{X}=$ ethylenediamine or 2,2' bipyridyl or 1,10-phenanthroline and cis- $\alpha-\left[\mathrm{Co}(\operatorname{trien})(\mathrm{Cl})_{2}\right] \mathrm{Cl}$ (trien: triethylene-tetramine) was dissolved in water. To this solution a slightly more than the calculated amount of tetradecylamine in ethanol was added drop by drop over a period of $30 \mathrm{~min}$. The mixture was set aside at room temperature for 2 days until no further colour change was observed. Afterwards a saturated solution of sodium perchlorate in very dilute perchloric acid was added. Slowly a pasty solid mass separates out and it was filtered off and washed with alcohol followed by acetone and dried over air. The semi-dried solid was further dried in a drying pistol over fused calcium chloride and stored in a vacuum desiccators. The structures of the phenanthroline, bipyridine containing surfactant-cobalt(III) complexes are shown in Scheme 1.

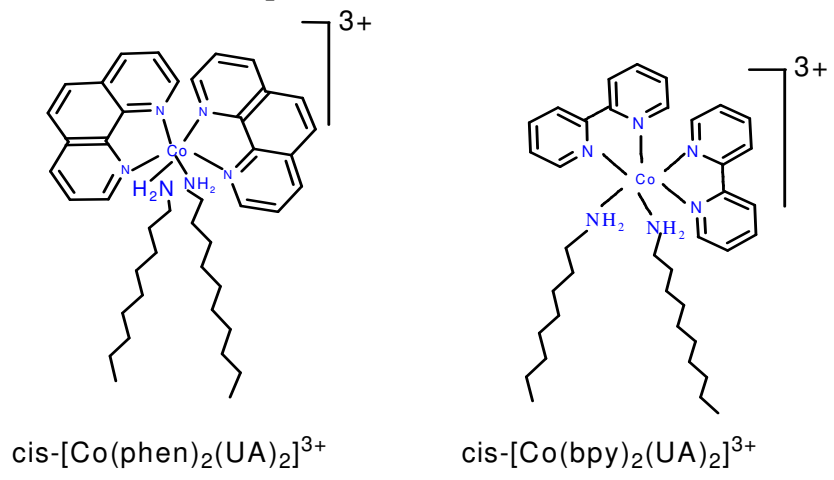

Scheme 1. The structures of the phenanthroline and bipyridine containing surfactantcobalt(III) complexes

Caution: Perchlorate salts of metal complexes with organic ligands are potentially explosive. Only small amounts of the material should be prepared and handled with great care. 


\section{Determination of critical micelle concentration}

The CMC values of the complexes were determined conductometrically using a specific conductivity meter. The conductivity cell was calibrated with $\mathrm{KCl}$ solutions in the appropriate concentration range. The cell constant was calculated using molar conductivity data for $\mathrm{KCl}^{31}$. Various concentrations of surfactant-cobalt(III) complexes were prepared in the concentration range $10^{-5}-10^{-1} \mathrm{~mol} \mathrm{dm}^{-3}$ in aqueous solution. The conductivity of these solutions was measured at 298, 308 and $318 \mathrm{~K}$. the temperature of the thermostat was maintained constant to within $\pm 0.01 \mathrm{~K}$. The conductance was measured after thorough mixing and temperature equilibrating at each dilution. The establishment of equilibrium was checked by taking a series of readings after 15 min until no significant change occurred.

\section{Microbial assay / testing of antimicrobial activity}

The in vitro antimicrobial screening of the surfactant-cobalt(III) complexes were tested for the microbial sensitivity to antibiotics is commonly tested using a disk diffusion test, employing antibiotic impregnated disks ${ }^{32}$. A similar test with sample laden disks was used in this study. The test solutions were prepared in sterile triple distilled water. This method was used to evaluate in vitro antibacterial and antifungal activity of test sample against certain human pathogenic microorganisms on Muller Hinton Agar (MHA) and Potato dextrose agar (PDA), respectively. The agar solution was sterilized by autoclaving at $15 \mathrm{lbs}$ pressure at $121{ }^{\circ} \mathrm{C}$ for $15 \mathrm{~min}$. Then nearly $20 \mathrm{~mL}$ of the medium was added into each sterilized Petri dish and allow to solidifying. After solidification of agar medium, $200 \mu \mathrm{L}$ of $(24 \mathrm{~h}$ fresh inoculum) test organisms were spread throughout the Petri dishes uniformly with a sterile glass spreader. To each disc the test samples were added with a sterile micropipette. $10 \mu \mathrm{L}$ of test solution of different concentrations were poured in each disk in three dishes. Each such dish contained two different concentrations $(0.001 \mathrm{~g} / \mathrm{disk})$ of test samples. The same process carried with all the five samples. The test sample coated disks (6-mm diameter) were placed in each dish by a sterilized forceps. One separate dish was used for control study by taking sterile triple distilled water only, without test sample. The dishes were rapped well by a paraffin film to seal them. The entire handling was done inside the laminar hood in front of a flame of a spirit lamp. The plates were incubated at $37 \pm 1{ }^{\circ} \mathrm{C}$ for $24-48 \mathrm{~h}$ (for bacteria) and $25 \pm 1^{\circ} \mathrm{C}$ for $72 \mathrm{~h}$ (for fungus). After incubation, the zone of inhibition was measured with Antibiotic Zone Scale $-\mathrm{C}$ and less than $10 \mathrm{~mm}$ zone was measured with ordinary ruler. The assays were performed in triplicate and the average values are presented. Penicillin G (10 mcg/disk - for bacteria) and Itraconazole (10 mg/disk - for fungus) antibiotic disk was used as positive control. The solvent (without sample) coated disk was used as negative control.

\section{Results and Discussion}

\section{Spectroscopic characterization}

The Infra red spectrum was used for the assignment of the geometrical configuration of the complexes. Several workers ${ }^{33,34}$ have employed the $\mathrm{NH}_{2}$ deformation mode in the $1700-1500 \mathrm{~cm}^{-1}$ region, $\mathrm{CH}_{2}$ rocking mode in the $900-850 \mathrm{~cm}^{-1}$ region and $\mathrm{Co}-\mathrm{N}$ stretching mode in the $610-500 \mathrm{~cm}^{-1}$ region to distinguish between cis and trans isomers. Baldwin $^{33}$ suggested that the cis isomers always show two peaks, whereas trans isomers usually have only one. Hughes and Mcwhinnie ${ }^{34}$ studied the IR absorption spectra of several bis(ethylenediamine complexes) and obtained a peak in $610-500 \mathrm{~cm}^{-1}$, where Co-N stretching mode of chelate ring is occur. Trans isomers had not more than three strong 
bands, but cis isomers have four and also occur as shoulders. Because of lower symmetry, the cis isomers show two bands for the $\mathrm{NH}_{2}$ deformation, two bands for the $\mathrm{NH} 2$ wagging modes and two bands for $\mathrm{CH}_{2}$ rocking mode and four bands as groups of two with a wide separation for the Co-N stretching mode. Complexes of the type cis- $\alpha-\left[\mathrm{Co}(\operatorname{trien})(\mathrm{UA})_{2}\right]^{3+}$ show two bands for $\mathrm{NH}_{2}$ deformation in the region 1750-1500 $\mathrm{cm}^{-1}$, two bands for the $\mathrm{CH}_{2}$ or $\mathrm{NH}_{2}$ twist mode in the region $1200-980 \mathrm{~cm}^{-1}$ and the $\mathrm{CH}_{2}$ rocking mode in the region $945-850 \mathrm{~cm}^{-1}$ as two bands ${ }^{35}$. Strukl and Walter ${ }^{36}$ and Schilt and Taylor ${ }^{37}$ studied the infrared spectra of several bipyridyl (bpy) and phenanthroline (phen) complexes. They observed that the spectral shape of the bpy and phen complexes were quite similar, taking into account the similarity of both ligands. The IR bands $\delta(\mathrm{C}-\mathrm{H}) 853 \mathrm{~cm}^{-1}, 737 \mathrm{~cm}^{-1}$ observed for phenanthroline are red shifted to 844 and $714 \mathrm{~cm}^{-1}$ in the surfactantcobalt(III)- phenanthroline complex. This shift can be explained by the fact that the nitrogen atoms of phennathroline donate a pair of electrons each to the central cobalt metal forming a coordinate covalent bond ${ }^{38}$. It is also confirmed by the shift of $v(\mathrm{C}-\mathrm{N})$ of phenathroline from about $1670 \mathrm{~cm}^{-1}$ and the free ligand to $1630 \mathrm{~cm}^{-1}$ after coordination ${ }^{39}$. The spectra of bipyridine complexes in general are less complicated than those of the phen complexes. Only three bands are present, one near $760 \mathrm{~cm}^{-1}$ ascribed to out of plane bending of ring hydrogens and one near $1450 \mathrm{~cm}^{-1}$ which is probably a ring frequency, and a ring frequency near $160 \mathrm{~cm}^{-1}$ for all the surfactant-cobalt(III) complexes, the bands exhibit around $2925 \mathrm{~cm}^{-1}$ and $2853 \mathrm{~cm}^{-1}$ can be assigned to $\mathrm{C}-\mathrm{H}$ asymmetric and symmetric stretching vibration of aliphatic $\mathrm{CH}_{2}$ of undecylamine. Perchlorate bands at ca. 1100 and $620 \mathrm{~cm}^{-1}$ belong to an ionic species that is the counter-ion is not involved in the cobalt-ligand coordination ${ }^{40}$. The IR spectroscopic data therefore clearly indicate a cisconfiguration for the surfactant- cobalt(III) complexes.

In the ${ }^{1} \mathrm{H}$ NMR spectrum of cis- $\left[\mathrm{Co}(\mathrm{en})_{2}\left(\mathrm{C}_{11} \mathrm{H}_{23} \mathrm{NH}_{2}\right)_{2}\right]\left(\mathrm{ClO}_{4}\right)_{3}$ (1) complex, due to the lower symmetry, methylene protons of ethylenediamine show a more complex absorption around 2.1-2.9 ppm. The methylene protons of the long chain moiety (tetradecylamine) give rise to a multiplet usually at 1.2-1.8 ppm, whereas the terminal methyl group of the hydrocarbon chain substituent gives a triplet around $0.85 \mathrm{ppm}$. The ${ }^{1} \mathrm{H}$ NMR spectral data for the cis- $\alpha-\left[\mathrm{Co}\right.$ (trien) $\left.\left(\mathrm{C}_{11} \mathrm{H}_{23} \mathrm{NH}_{2}\right)_{2}\right]\left(\mathrm{ClO}_{4}\right)_{3}$ (2) complex, exhibit signals in the region 2.5-3.2 ppm attributable to the $-\mathrm{CH}_{2}$ group of the triethylenetetramine chelate ring. In the ${ }^{1} \mathrm{H}$ NMR spectrum of cis- $\left[\mathrm{Co}(\mathrm{bpy})_{2}\left(\mathrm{C}_{11} \mathrm{H}_{23} \mathrm{NH}_{2}\right)_{2}\right]\left(\mathrm{ClO}_{4}\right)_{3}(3)$ and cis- $\left[\mathrm{Co}(\mathrm{phen})_{2}\left(\mathrm{C}_{11} \mathrm{H}_{23} \mathrm{NH}_{2}\right)_{2}\right]$ $\left(\mathrm{ClO}_{4}\right)_{3}(4)$ complexes, the aromatic protons appear in the region 7-10 ppm and assigned in a manner similar to the case of their respective paranet complexes ${ }^{41,42}$. The protons of long chain moiety (tetradecylamine) appear in the same region like surfactant-cobalt(III)ethylenediamine and triethylenetetramine complexes.

The ${ }^{13} \mathrm{C}$ NMR spectra of surfactant-cobalt(III) complexes exhibit only one signal around 35-40 ppm because of merging of tetradecylamine and chelating ligand signals. For long chain tetradecylamine, the aliphatic methylene carbons of all the surfactant cobalt(III) complexes appeared around 15-40 ppm and the terminal carbon atom appeared around $14 \mathrm{ppm}$. The ${ }^{13} \mathrm{C}$ NMR spectra of cis- $\left[\mathrm{Co}(\text { phen })_{2}\left(\mathrm{C}_{11} \mathrm{H}_{23} \mathrm{NH}_{2}\right)_{2}\right]\left(\mathrm{ClO}_{4}\right)_{3}(4)$ and cis- $\left[\mathrm{Co}(\mathrm{bpy})_{2}\right.$ $\left.\left(\mathrm{C}_{11} \mathrm{H}_{23} \mathrm{NH}_{2}\right)_{2}\right]\left(\mathrm{ClO}_{4}\right)_{3}$ (3) complexes, exhibit signals in the aromatic region (130-160 ppm) corresponding to phenanthroline/bipyridine rings.

\section{CMC determination}

The CMC values were computed from the slope of [Co(III)] versus specific conductance data. The complex concentration at which the micellization starts was evident from the change in the 
slope of the plot; that particular concentration is the CMC under the experimental conditions. The CMC values were determined at three different temperatures (298, 308 and $318 \mathrm{~K})$. At all temperatures a break in the conductance versus concentration plots, characteristic of micelle formation, was observed. The CMC values were determined by fitting the data points above and below the break to $\mathrm{y}=\mathrm{mx}+\mathrm{c}$ and solving the two equations simultaneously to obtain the point of intersection. Least squares analysis was employed and correlation coefficients were greater than 0.98 in all cases. Conductivity measurements at three different temperatures were repeated three times and the accuracy of the $\mathrm{CMC}$ values was found within $\pm 3 \%$ error. Figure 1 illustrates the plot for cis- $\left[\mathrm{Co}\left(\mathrm{en}_{2}\right)_{2}\left(\mathrm{C}_{11} \mathrm{H}_{23} \mathrm{NH}_{2}\right)_{2}\right]\left(\mathrm{ClO}_{4}\right)_{3}$; similar plots (not shown) were obtained for the remaining complexes.

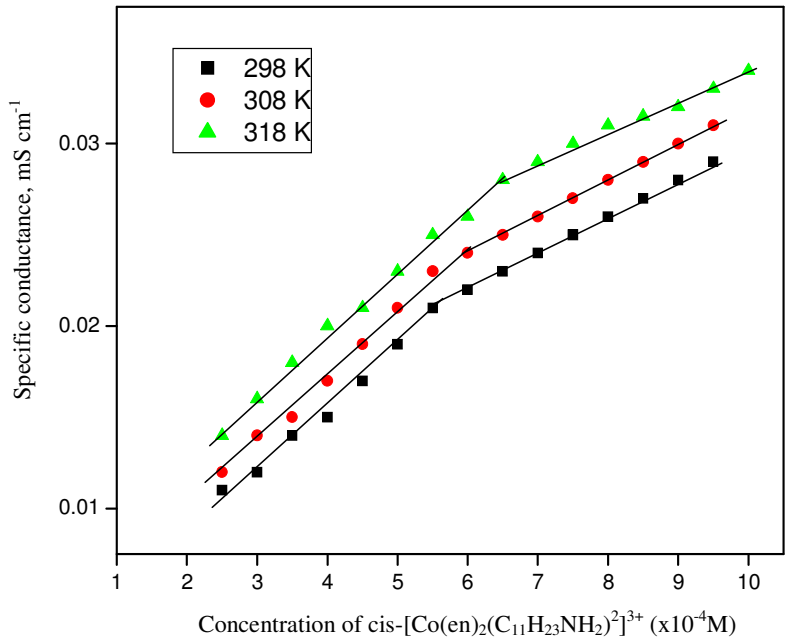

Figure 1. Plot of concentration versus specific conductance of surfactant-cobalt(III) complex cis- $\left[\mathrm{Co}(\mathrm{en})_{2}\left(\mathrm{C}_{11} \mathrm{H}_{23} \mathrm{NH}_{2}\right)_{2}\right]\left(\mathrm{ClO}_{4}\right)_{3}$ in aqueous solution

This behavior may be related to two competitive effects. Firstly, a temperature increase causes a decrease in hydration in the hydrophilic group, which favors micellization. Secondly, a temperature increase also disrupts the water surrounding the hydrophobic group and this retards micellization. The relative magnitude of these two opposing effects will determine CMC behavior. The structures of the complex before and after CMC are shown in Scheme 2.

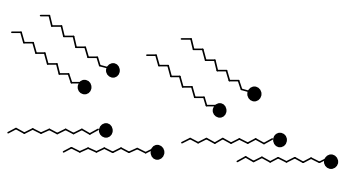

below cmc(low conc)

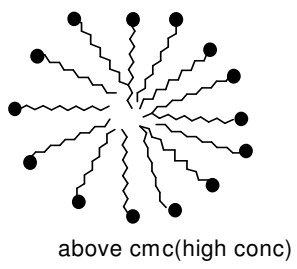

above $\mathrm{cmc}$ (high conc)

- Surfactant-cobalt(III) complex ions

Scheme 2. The structures of the complex before and after CMC

Griffiths et al. have reported ${ }^{43}$ the CMC values of the 1,4,7,10 tetraazacyclododecane and 1,4,7 triazacyclononane derivatives. In these derivatives a small difference in the head group structure have a large effects on the CMC values and also CMC values decreased to approximately two times for every additional methylene residue in the hydrophobic group. As mentioned in our previous reports ${ }^{44-46}$, the CMC values (Table 2) for surfactant- 
cobalt(III) complexes in the present study are also very low compared to that of the simple organic surfactants. Thus it is suggested that these metal surfactant complexes have more capacity to associate themselves forming aggregates compared to those of ordinary synthetic organic surfactants. Moreover, introduction of a metal complex to the hydrophilic part of the amphiphile can remarkably enhance the ability of aggregation.

Table 2. CMC values and thermodynamic parameters

\begin{tabular}{|c|c|c|c|c|c|c|c|}
\hline \multirow{2}{*}{ 宏 } & \multirow{2}{*}{$\begin{array}{l}\text { Surfactant- } \\
\text { cobalt(III) } \\
\text { complexes }\end{array}$} & \multicolumn{3}{|c|}{$\mathrm{CMC}, \mathrm{mol} \mathrm{dm}{ }^{-3}$} & \multicolumn{3}{|c|}{$\begin{array}{c}\text { Thermodynamic } \\
\text { parameters }\end{array}$} \\
\hline & & $298 \mathrm{~K}$ & $308 \mathrm{~K}$ & $318 \mathrm{~K}$ & $\begin{array}{c}\Delta \mathrm{G}_{\mathrm{m}}^{0} \\
\mathrm{~kJ} \mathrm{~mol}^{-1}\end{array}$ & $\begin{array}{c}\Delta \mathrm{H}_{\mathrm{m}}^{0} \\
\mathrm{~kJ} \mathrm{~mol}^{-1}\end{array}$ & $\begin{array}{c}\Delta \mathrm{S}_{\mathrm{m}}^{0} \\
\mathrm{~kJ} \mathrm{~mol}^{-1}\end{array}$ \\
\hline 1 & $\begin{array}{l}\text { cis- }\left[\operatorname{co}(\mathrm{en})_{2}\right. \\
\left.\left(\mathrm{C}_{11} \mathrm{H}_{23} \mathrm{NH}_{2}\right)_{2}\right]^{3+}\end{array}$ & $5.48 \times 10^{-4}$ & $5.97 \times 10^{-4}$ & $6.50 \times 10^{-4}$ & -38.22 & -39.5 & 7.83 \\
\hline 2 & $\begin{array}{l}\text { cis- } \alpha \text { - }[\text { co(trien) } \\
\left.\left(\mathrm{C}_{11} \mathrm{H}_{23} \mathrm{NH}_{2}\right)_{2}\right]^{3+}\end{array}$ & $4.48 \times 10^{-4}$ & $4.99 \times 10^{-4}$ & $5.47 \times 10^{-4}$ & -41.18 & -30.9 & 15.17 \\
\hline 3 & $\begin{array}{l}\text { cis- }\left[\mathrm{co}(\mathrm{bpy})_{2}\right. \\
\left.\left(\mathrm{C}_{11} \mathrm{H}_{23} \mathrm{NH}_{2}\right)_{2}\right]^{3+}\end{array}$ & $9.85 \times 10^{-5}$ & $1.01 \times 10^{-4}$ & $1.48 \times 10^{-4}$ & -43.7 & -27.8 & 22.90 \\
\hline 4 & $\begin{array}{l}\text { cis- }\left[\mathrm{co}(\mathrm{phen})_{2}\right. \\
\left.\left(\mathrm{C}_{11} \mathrm{H}_{23} \mathrm{NH}_{2}\right)_{2}\right]^{3+}\end{array}$ & $8.86 \times 10^{-5}$ & $9.93 \times 10^{-5}$ & $1.2 \times 10^{-4}$ & -45.8 & -14.3 & 40.14 \\
\hline
\end{tabular}

\section{Thermodynamics of micellization}

Shehata et al. ${ }^{23}$ have reported the CMC values of some novel surfactant complexes along with the thermodynamic parameters of micelle formation, standard free energy, standard enthalpy and standard entropy of micelle formation. The study of CMC versus temperature is often undertaken to obtain information on hydrophobic and head group interactions. This involves deriving various thermodynamic parameters of micelle formation. The change in the CMC with temperature is generally analyzed in terms of the phase separation or the equilibrium model for micelle formation ${ }^{47-49}$. According to these models, the standard Gibbs free energy of micelle formation per mole of monomer, $\triangle \mathrm{G}^{0} \mathrm{~m}$, is given by

$$
\triangle \mathrm{G}_{\mathrm{m}}^{0}=\mathrm{RT}\left(2-\alpha_{\text {ave }}\right) \ln \mathrm{CMC} \text {, }
$$

Where $\mathrm{R}, \mathrm{T}$ and $\alpha_{\text {ave }}$ are gas constant, absolute temperature and average degree of micellar ionization (The micelle ionization degree at the CMC, was obtained as the ratio between the slopes of the nearly linear specific conductance versus [complex] plots above and below the $\mathrm{CMC}^{50}$, respectively). The enthalpy of micelle formation can be obtained by applying the Gibbs-Helmholtz, equation to Eq. (1)

$$
\triangle \mathrm{H}_{\mathrm{m}}^{0}=-\mathrm{RT}^{2}\left(2-\alpha_{\text {ave }}\right) \mathrm{d} \ln \mathrm{CMC} / \mathrm{d} \mathrm{T}
$$

Once the Gibbs free energy and the enthalpy of micelle formation are obtained, obviously the entropy of micelle formation can be determined by

$$
\triangle \mathrm{S}_{\mathrm{m}}^{0}=\left(\triangle \mathrm{H}_{\mathrm{m}^{-}}^{0} \triangle \mathrm{G}_{\mathrm{m}}^{0}\right) / \mathrm{T} \text {, }
$$

The thermodynamic parameters of micellization for the surfactant-cobalt(III) complexes are compiled in Table 2. The observed more negative Gibbs free energy of micellization indicates more favored micellization for the system under study. Moreover, since the changes of CMC with temperature are small, the value of $\triangle \mathrm{H}^{0}{ }_{\mathrm{m}}$ and $\triangle \mathrm{S}_{\mathrm{m}}^{0}$ must be rather inaccurate and should be considered as only approximate. Nusselder and Engberts ${ }^{51}$ have 
suggested that for negative $\triangle \mathrm{H}^{0} \mathrm{~m}$ values, London-dispersion forces play a major role in the micelle formation. Positive values of $\triangle S^{0}$ clearly indicate that the micellization of the studied surfactants in aqueous solution is governed mainly by hydrophobic interactions between the surfactant cations, resulting in the breakdown of the structured water surrounding the hydrophobic groups and indicates that the cationic surfactant formation is entropy driven process.

\section{Antimicrobial activity of surfactant sample against microorganisms}

The surfactant-cobalt(III) complexes (1-4) were screened in vitro for their microbial activity against certain pathogenic bacterial and fungal species using disc diffusion method The antimicrobial activity of surfactant samples was scrutinized with various pathogenic microorganisms using the disk diffusion test. In this work, we used ten pathogens, this is known as notorious pathogens causing serious disease to human. The inhibition zone reflects magnitude of susceptibility of the microorganism. The strains susceptible to disinfectants exhibit larger inhibition zone, whereas resistant strains exhibit smaller inhibition zone. The activity of surfactantcobalt (III) complexes may be due to an efficient diffusion of the metal complexes into the baterial /fungal cells and/or interaction with the bacterial/fungal cells ${ }^{52}$. The test solutions were prepared in dimethyl sulphoxide (1\%) and the results of the antimicrobial activities are summarized in Table 3.

In our study, the surfactant-metal complexes 1 and 2 were most effective against all the strains while less effect was noticed from 3 and 4 (Table 3). However, the method illustrates the potential biocidal effect of sample to different microbial strains. Most of the pathogens were highly affected by all the test samples fortunately nil effect was not observed. Concentration-dependent manner play a vital role in antimicrobial activity of Surfactant samples but there is no greater difference occurred between the both concentrations. Commonly, in our results, Surfactant samples were most effective against some bacterial pathogens such as Micrococcus luteus (B3) and Enterococcus faecalis (B4). The minimum level effect was noticed from Salmonella typhimurium (B1) and Shigella flexneri (B5) (Table 3). In fungus, higher activity was observed in Candida glabrata (F2) with all the samples. Comparing with the positive control (Itraconazole), all the samples showed a higher inhibition effect against all the fungal pathogens in both concentrations and significant inhibition was observed in surfactant-metal complex 4 (Table 3). Similar observations were also recorded in bacteria with Penicillin G, except B1 and B3.

Table 3. Antimicrobial activities of surfactant-cobalt(III) complexes (1-4)

\begin{tabular}{lccccc}
\hline \multirow{2}{*}{ Test organisms } & \multicolumn{5}{c}{ Diameter of inhibition zone, nm } \\
\cline { 2 - 6 } & \multicolumn{5}{c}{ Surfactant-cobalt(III) complexes } \\
\cline { 2 - 6 } & 1 & 2 & 3 & 4 & standard \\
\hline Antibacterial activity & 17 & 17 & 20 & 19 & 17 \\
Salmonella typhimurium B & 21 & 23 & 20 & 18 & 12 \\
Vibrio cholerae B2 & 38 & 38 & 40 & 36 & 34 \\
Micrococcus luteus B3 & 23 & 39 & 21 & 23 & 15 \\
Enterococcus faecalis B4 & 20 & 20 & 20 & 20 & 14 \\
Shigella flexneri B5 & & & & & \\
Antifungal activity & 23 & 23 & 18 & 19 & 13 \\
Candida albicans F1 & 28 & 23 & 22 & 22 & $8^{*}$ \\
Candida glabrata F2 & 24 & 22 & 17 & 17 & $9^{*}$ \\
Cryptococcus sp F3 & 20 & 17 & 19 & 17 & 10 \\
Microsporum canis F4 & 22 & 19 & 20 & 16 & 11 \\
Epidermophyton floccosum F5 & &
\end{tabular}

Standard-pencillin-G for bacteria Itraconazole for fungus, *Less than $10 \mathrm{~mm}$ were measured by ordinary ruler 
Senthil Kumar et $a l .{ }^{53}$ reported that surfactant-cobalt(III) complexes are in general capable of inhibiting the growth of bacteria and fungi to a moderate extent. However, Salmonella typhimurium (B1) was got mild inhibition effect against surfactant-metal complexes1 and 2. Now a day, various microorganisms have evolved drug resistance over many generations. Therefore, an alternative treatment material to overcome the drug resistance of various microorganisms is needed desperately, especially in disease treatment process. The obtained result clearly revealed that the growth of microbes is highly inhibited by all the test samples. There is no antimicrobial activity in solution devoid of sample used as a vehicle control (solvent alone solution), reflecting that antimicrobial activity was directly related to the sample. It may be concluded that the test samples are best alternative to antibiotics for the treatment.

\section{References}

1. Griffiths P C, Fallis I A, Chuenpratoom T and Watanesk R, Adv Colloid Interface Sci., 2006, 122, 107-117.

2. Gutierrez D D, Surtchev M, Eiser E and Elsevier C J, Nano Lett., 2006, 6, 145-147.

3. Donnio B, Curr Opin Colloid Interface Sci., 2002, 7, 371-394.

4. Bowers J, Amos K E, Bruce D W and Heenan R K, Langmuir, 2005, 21, 5696-5706.

5. Bowers J, Danks M J, Bruce D W and Heenan R K, Langmuir, 2003, 19, 292-298.

6. Bowers J, Amos K E, Bruce D W and Webster J R P, Langmuir, 2005, 21, 1346- 1353.

7. Behm C A, Creaser I, Daszkiewicz B, Geue R J, Sargeson A M and Walker G W, J Chem Soc Chem Commun., 1993, 24, 1844-1846.

8. Behm C A, Boreham P F L, Creaser I I, Daszkiewicz B, Maddalena D J, Sargeson A M and Snowdown M, Aust J Chem., 1995, 48, 1009-1030.

9. Ghirlanda G, Scrimin P, Tecillam P and Toffoletti A, Langmuir, 1998, 14, 1646-1655.

10. Walker G W, Geue R J, Sargeson A M and Behm C A, J Chem Soc Dalton Trans., 2003, 15, 2992-3001.

11. Storrs R W, Tropper F D, Li H Y, Song C K, Kunjyoshi J K, Sipkins D A, Li K C P, and Bednarski M D, J Am Chem Soc., 1995, 117, 7301-7306.

12. Kunjappu J T, Kelkar V K and Manohar C, Langmuir, 1993, 9(1), 352-354.

13. Wang P, Klein C, Moser J E, Baker R H, Ha N C, Charvet R, Comte P, Zakeeruddin S M and Gratzel M, J Phys Chem B, 2004, 108, 17553-17559.

14. Jaeger D A, Reddy V B, Arulsamy N and Bhole S, Langmuir, 1998, 14, 2589-2592.

15. Xie J Q, Xu B, Xie B, Wei H and Zeng X.C, J Dispersion Sci Technol., 2006, 27(4), 481-487.

16. Yashiro M, Matsumoto K, Seki N and Yoshikawa S, Bull Chem Soc Jpn., 1993, 66, 1559-1562.

17. Behm C A, Creaser I I, Daszkeiwicz K B, Geue R J, Sargeson A M and Walker G W, J Chem Soc Chem Commun., 1993, 24, 1844-1846.

18. Bruce D W, Denby I R, Tiddy G J T and Watkins J M, J Mater Chem., 1993, 3, 911-916.

19. Sprintschnik G, Sprintschnik H W, Kirsch P P and Whitten D G, J Am Chem Soc., 1977, 99, 4947-4954 and references therein.

20. Viscardi G, Quagliotto P, Barolo C, Savarino P, Barni E and Fisicaro E, J Org Chem., 2000, 65(24), 8197-8203.

21. Wanless E J and Phasley R M, Colloids Surf., 1991, 56, 201-215.

22. Fallis I A, Griffiths P C, Griffithis P M, Hibbs D E, Hurthouse M B and Winnington A L, Chem. Commun., 1998, 665-666. 
23. Shehata H A, Wahab A E, Haffiz A A, Aiad I and Hegazy M A, J Surf Deterg., 2008, 11, 139-144.

24. Deegan C, McCann M, Devereux M, Coyle B and Egan D A, Cancer Lett., 2007, 247, 224-233.

25. McCann M, Geraghty M, Devereux M, O'Shea D, Mason J and O'Sullivan L, Met Based Drugs., 2000, 7, 185-193.

26. Dwyer F P, Reid I K, Shulman A, Laycock G M and Dixson S, Aust J Expt Biol Med Sci., 1969, 47, 203-218.

27. Nagababu P and Satyanarayana S, Polyhedron, 2007, 26(8), 1686-1692.

28. Arumugam M N and Arunachalam S, Indian J Chem., 1997, 36A, 84 \&, 315-316.

29. Santhakumar K, Kumaraguru N, Arunachalam S and Arumugham M N, Polyhedron, 2006, 25, 1507-1513.

30. Kumaraguru N, Arunachalam S, Arumugham M N and Santhakumar K, Trans Met Chem., 2006, 31, 250-255.

31. Barthel J, Feuerlein F, Neueder R and Wachter R, J Solution Chem., 1980, 9, 209-219.

32. Case C L and Johnson T R, Laboratory Experiments in Microbiology, Benjamin Ummings Pub Inc, California, 1984, 126.

33. Baldwin M E, J Chem Soc., 1960, 4369-4376.

34. Hughes M N and McWhinnie W R, J Inorg Nucl Chem., 1966, 28(8), 1659-1665.

35. Buckingham D A and Jones D, Inorg Chem., 1965, 4, 1387-1392.

36. Strukl J S and Walter J L, Spectrochim Acta Part A, 1971, 27(2), 223-238.

37. Schilt A A and Taylor R C, J Inorg Nucl Chem., 1959, 9, 211-221.

38. Jin L and Yang P, Polyhedron, 1997, 16, 3395-3398.

39. Gerber T I A, Abrahams A, Mayer P and Hosten E, J Coord Chem., 2003, 56, 1397-1407.

40. Rosenthal M R, J Chem Educ., 1973, 50, 331-335.

41. Ghosh S, Barve A C, Kumbhar A A, Kumbhar A S, Puranik P A, Datar V G, Sonawane U B and Joshi R R, J Inorg Biochem., 2006, 100, 331-343.

42. Castelleno S, Gunther H and Ebersole S, J Phys Chem., 1965, 69(12), 4166-4176.

43. Griffiths P C, Fallis I A, Chuenpratoom T and Watanesk R, Adv Colloid Int Sci., 2006, 122, 107-117.

44. Santhakumar K, Kumaraguru N, Arunachalam S and Arumugham M N, Polyhedron, 2006, 25, 1507-1513.

45. Kumaraguru N, Arunachalam S, Arumugham M N and Santhakumar K, Trans Met Chem., 2006, 31, 250-255.

46. Sasikala K, Senthilkumar R and Arunachalam S, Z Phys Chem., 2010, 224, 999-1009.

47. Mukerjee P, J Phys Chem., 1962, 66, 1375-1376.

48. Galan J J, Perez A G and Rodriguez J R, J Therm Anal Calorim., 2003, 72, 465-470.

49. Perez A G, Castillo J D, Czapkiewicz J and Rodrique J, Colloid Polym Sci., 2002, 280(6), 503-508.

50. Zana R, J Colloid Interface Sci., 1980, 78(2), 330-337.

51. Nusselder J J H and Engberts J B F N, J Colloid Interface Sci., 1992, 148, 353-361.

52. Chohan Z H, Shaikh A U and Supuran C T, J Enz Inhib Med Chem., 2006, 21, 733-740.

53. Senthil Kumar R, Arunachalam S, Periasamy V S, Preethy C P, Riyasdeen A and Akbarsha M A, J Inorg Biochem., 2009, 103(1), 117-127. 